\title{
GPx3 supports ovarian cancer progression by manipulating the extracellular redox environment
}

\author{
Beth L. Worley ${ }^{\mathrm{a}, 1}$, Yeon Soo Kim ${ }^{\mathrm{a}, 1}$, Jennifer Mardini ${ }^{\mathrm{a}}$, Rameez Zaman ${ }^{\mathrm{a}}$, Kelly E. Leon ${ }^{\mathrm{b}}$, \\ Piyushi Gupta Vallur ${ }^{\mathrm{a}}$, Asvelt Nduwumwami ${ }^{\mathrm{a}}$, Joshua I. Warrick ${ }^{\mathrm{c}}$, Patrick F. Timmins ${ }^{\mathrm{d}}$, \\ Joshua P. Kesterson ${ }^{\mathrm{e}}$, Rébécca Phaëton ${ }^{\mathrm{e}, \mathrm{f}}$, Nam Y. Lee ${ }^{\mathrm{g}}$, Vonn Walter ${ }^{\mathrm{h}, \mathrm{i}}$, Lauren Endres ${ }^{\mathrm{j}}$, \\ Karthikeyan Mythreye ${ }^{\mathrm{k}}$, Katherine M. Aird ${ }^{\mathrm{b}}$, Nadine Hempel ${ }^{\mathrm{a}, \mathrm{e}, *}$
}

${ }^{a}$ Department of Pharmacology, Pennsylvania State University College of Medicine, Hershey, PA, USA

${ }^{\mathrm{b}}$ Department of Molecular and Cellular Physiology, Pennsylvania State University College of Medicine, Hershey, PA, USA

${ }^{\mathrm{c}}$ Department of Pathology, Pennsylvania State University College of Medicine, Hershey, PA, USA

${ }^{\mathrm{d}}$ Womens Cancer Care Associates, Albany, NY, USA

${ }^{\mathrm{e}}$ Department of Obstetrics and Gynecology, Pennsylvania State University College of Medicine, Hershey, PA, USA

${ }_{\mathrm{f}}^{\mathrm{f}}$ Department of Microbiology and Immunology, Pennsylvania State University College of Medicine, Hershey, PA, USA

${ }^{\mathrm{g}}$ Department of Pharmacology, College of Medicine, University of Arizona, Tucson, AZ, USA

${ }^{\mathrm{h}}$ Department of Public Health Sciences, Pennsylvania State University College of Medicine, Hershey, PA, USA

${ }^{\mathrm{i}}$ Department of Biochemistry and Molecular Biology, Pennsylvania State University College of Medicine, Hershey, PA, USA

${ }^{\mathrm{j}}$ Department of Biology and Chemistry, SUNY Polytechnic Institute, Utica, NY, USA

${ }^{\mathrm{k}}$ Department of Chemistry and Biochemistry, University of South Carolina, Columbia, SC, USA

\section{A R T I C L E I N F O}

\section{Keywords:}

Extracellular glutathione peroxidase

GPx3

Ovarian cancer

Ascites

Ascorbate

\begin{abstract}
A B S T R A C T
Ovarian cancer remains the most lethal gynecologic malignancy, and is primarily diagnosed at late stage when considerable metastasis has occurred in the peritoneal cavity. At late stage abdominal cavity ascites accumulation provides a tumor-supporting medium in which cancer cells gain access to growth factors and cytokines that promote survival and metastasis. However, little is known about the redox status of ascites, or whether antioxidant enzymes are required to support ovarian cancer survival during transcoelomic metastasis in this medium. Gene expression cluster analysis of antioxidant enzymes identified two distinct populations of highgrade serous adenocarcinomas (HGSA), the most common ovarian cancer subtype, which specifically separated into clusters based on glutathione peroxidase 3 (GPx3) expression. High GPx3 expression was associated with poorer overall patient survival and increased tumor stage. GPx3 is an extracellular glutathione peroxidase with reported dichotomous roles in cancer. To further examine a potential pro-tumorigenic role of GPx3 in HGSA, stable OVCAR3 GPx3 knock-down cell lines were generated using lentiviral shRNA constructs. Decreased GPx3 expression inhibited clonogenicity and anchorage-independent cell survival. Moreover, GPx3 was necessary for protecting cells from exogenous oxidant insult, as demonstrated by treatment with high dose ascorbate. This cytoprotective effect was shown to be due to GPx3-dependent removal of extracellular $\mathrm{H}_{2} \mathrm{O}_{2}$. Importantly, GPx3 was necessary for clonogenic survival when cells were cultured in patient-derived ascites fluid. While oxidation reduction potential (ORP) of malignant ascites was heterogeneous in our patient cohort, and correlated positively with ascites iron content, GPx3 was required for optimal survival regardless of ORP or iron content. Collectively, our data suggest that HGSA ovarian cancers cluster into distinct groups of high and low GPx3 expression. GPx3 is necessary for HGSA ovarian cancer cellular survival in the ascites tumor environment and protects against extracellular sources of oxidative stress, implicating GPx3 as an important adaptation for transcoelomic metastasis.
\end{abstract}

\footnotetext{
* Corresponding author at: Department of Pharmacology, Pennsylvania State University College of Medicine, Hershey, PA, USA.

E-mail address: nhempel@psu.edu (N. Hempel).

${ }^{1}$ Co-first author.
} 

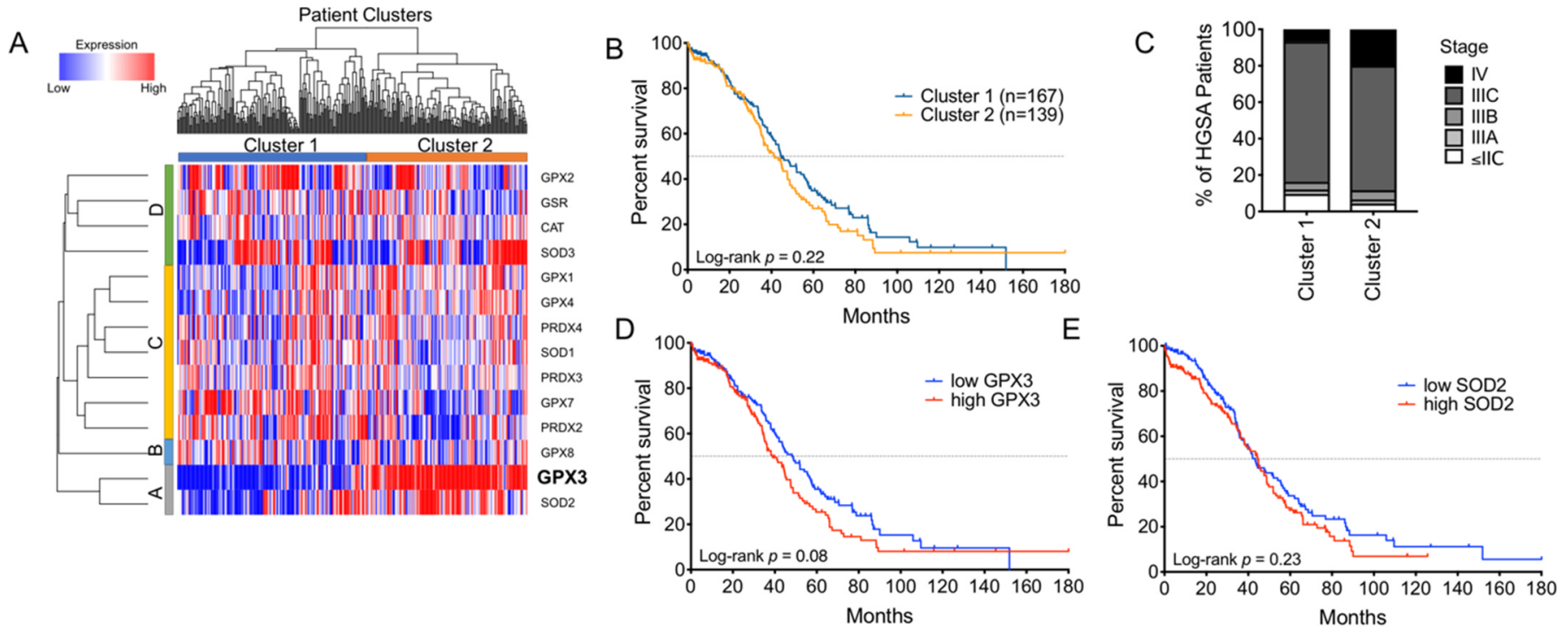

Fig. 1. Ovarian cancer specimens fall into two distinct clusters based on expression of the extracellular antioxidant GPx3. A: Hierarchical cluster analysis of antioxidant gene expression separates high grade serous adenocarcinoma patient samples into two distinct clusters (TCGA RNA sequencing data log2 transformed). B: Kaplan-Meier analysis of overall survival cluster 1 and cluster 2 patients (Log-rank Mantel-Cox test, HR: 1.20 [95\% CI: 0.90-1.61]). C: Percentages of different tumor stages at diagnosis of patients in cluster 1 and cluster 2. D: High GPx3 expression is negatively associated with patient survival. TCGA RNA sequencing samples were sorted above (high) and below (low) median GPx3 expression, and stratified in Kaplan Meier plot by overall survival (Log-rank Mantel-Cox test, HR: 1.30 [95\% CI: 0.97-1.75]). E: Kaplan Meier plot comparing overall survival of patients with high and low SOD2 expression. (Log-rank Mantel-Cox test, HR: 1.03 [95\% CI: (0.89-1.60]).

\section{Introduction}

Ovarian cancer is the fifth-leading cause of death in women due to cancer in the United States, with 14,000 anticipated deaths in 2018 [1]. It is also the most lethal gynecologic malignancy, with a 5-year overall survival rate of less than $27 \%$ for stage IV patients with the most common histological subtype, high grade serous adenocarcinoma (HGSA) [1]. While early stage cases have a much improved prognostic outlook, $60 \%$ of patients are diagnosed at stages $>$ III, owing to the lack of effective screening methods and asymptomatic progression of the disease until significant metastasis has developed throughout the peritoneal cavity [1].

In addition to widespread metastatic lesions in peritoneal organs such as the omentum, late stage disease is also characterized by the accumulation of abdominal ascites. The appearance of ascites correlates negatively with patient outcome and therapeutic resistance [2,3]. Moreover, metastatic tumor cells are commonly found within this fluid and are thus thought to use this transcoelomic spread as a major route for dissemination in the peritoneal cavity [4]. To enable successful metastasis, cell must overcome anchorage-independent apoptosis (anoikis) and adapt to deal with stress associated with changing tumor micro environments. Evidence suggests that antioxidants provide protection against oxidative stress associated with metastatic progression. For example, N-acetyl-L-cysteine improves survival of matrix detached cancer cells and significantly increase metastatic burden in vivo $[5,6]$. Moreover, intrinsic changes in tumor cell antioxidant enzyme expression is observed during metastatic progression in a number of tumor types [7-10].

It is now widely acknowledged that ascites provide a tumor-supporting medium containing growth factors and cytokines that have been shown to promote survival, proliferation and metastasis of ovarian cancer cells [11]. For example, IL-6 and lysophosphatidic acid (LPA) are highly enriched in patient ascites, and associated with chemoresistance and reduced progression-free survival [12,13]. Among other mechanisms, LPA induces expression of cytokines and promotes cell proliferation through de novo lipogenesis $[14,15]$. Due to the presence of stromal and immune cells and high expression of pro-inflammatory cytokines, it has been proposed that the ascites environment is also marked by oxidative stress. A recent study demonstrated that 8-isoprostane levels are significantly elevated in ascites compared to normal serum [16]. However, it was also noted that total antioxidant capacity was concomitantly elevated in patient ascites [16]. This suggests that extracellular oxidant scavenging is a phenotype of malignant ovarian cancer, and that survival in ascites may therefore require the expression of antioxidant enzymes by ovarian cancer cells suspended in this fluid. However, it remains unclear if a particular antioxidant gene expression signature is associated with metastatic ovarian cancer.

To address this, we analyzed HGSA ovarian cancer RNA expression data from the cancer genome atlas (TCGA), which revealed that tumors fall into two distinct clusters of antioxidant enzyme expression based on high and low glutathione peroxidase 3 (GPx3) expression. GPx3 was the only antioxidant enzyme where high expression negatively associated with patient overall survival. While GPx3 has been described to have tumor suppressive functions in several cancer types [17-22], there is evidence that increased expression is associated with ovarian clear cell carcinoma chemoresistance $[23,24]$, and that high levels can be found in the ascites of advanced serous ovarian cancer patients [25]. Since GPx3 is the primary extracellular selenocysteine containing glutathione peroxidase [26], we set out to examine the role of GPx3 as a pro-tumorigenic protein in the context of the ovarian cancer ascites tumor environment.

\section{Materials and methods}

\subsection{TCGA cluster analysis}

TCGA data were accessed through cBioPortal.org [27]. RSEM gene expression quantification values for antioxidant genes of interest in the TCGA cohort $(n=603)$ were log-transformed using log2(RSEM +1 ) and median centered by gene. Antioxidant enzymes that were not detected or those that displayed little variability across TCGA specimens were excluded. The data were hierarchically clustered using average linkage and a dissimilarity metric equal to $(1-\rho) / 2$, where $\rho$ is the Pearson correlation coefficient. Manual review of the resulting dendrogram (Fig. 1) identified two main clusters of subjects. Kaplan Meier curves were generated using GraphPad Prism software and statistical 
Table 1

GPx3 shRNA construct ID and sequences.

\begin{tabular}{llll}
\hline shRNA & Construct ID & Sequence & Location \\
\hline$\# 1$ & $\underline{\text { TRCN0000008676 }}$ & GCCTCCAAATATTAGTAACTA & 3'UTR \\
$\# 2$ & $\underline{\text { TRCN0000008678 }}$ & GTGGAGGCTTTGTCCCTAATT & CDS \\
$\# 3$ & $\underline{\text { TRCN0000008677 }}$ & GCTGGCAAATACGTCCTCTTT & CDS \\
$\# 4$ & $\underline{\text { TRCN0000008680 }}$ & GTGGCATAAGTGGCACCATTT & CDS \\
\hline
\end{tabular}

differences in overall survival determined using log rank (Mantel-Cox test).

\subsection{Cell culture and generation of stable GPx3 knock-down cell lines}

All ovarian cancer cell lines were cultured, as previously reported [28]. Briefly, NIH:OVCAR-3 cells (referred here as OVCAR3) were obtained from American Type Culture Collection (ATCC HTB-161) and maintained in RPMI 1640 medium (Gibco, 11875-093) containing 10\% fetal bovine serum (FBS; Hyclone, SH30070.03) and 1\% penicillin/ streptomycin. 293FT cells were maintained in DMEM containing $10 \%$ FBS, $4.5 \mathrm{~g} / \mathrm{L}$ glucose, $2 \mathrm{mM}$ L-glutamine, and $1 \mathrm{mM}$ sodium pyruvate (Corning, 10-013-CV). All cell lines were cultured in a $5 \% \mathrm{CO}_{2}$ environment at $37^{\circ} \mathrm{C}$. To generate stable GPx3 knock-down cells, lentivirus was packaged in 293FT cells using the ViraPower Kit (Invitrogen, Carlsbad, CA), according to manufacturer's instructions. Four different shRNA clones were utilized (Sigma-Aldrich, Table 1), with shGPx3 \#1 and \#2 displaying strongest GPx3 knockdown, as determined by semiquantitative real-time RT-PCR (Fig. S1). These were used for subsequent generation of GPx3 knock-down cell lines, by infecting $5 \times 10^{5}$ OVCAR3 cells with lentivirus-containing supernatant \#1, \#2, or empty backbone pLKO.1 (Addgene plasmid \#8453) for $24 \mathrm{~h}$, followed by puromycin selection $(1 \mu \mathrm{g} / \mathrm{mL})$ for 2 weeks.

\subsection{RNA isolation and semi-quantitative real-time RT-PCR}

Total RNA was extracted using the Qiagen RNeasy Mini Kit (Qiagen, Hilden, Germany) according to manufacturer's instructions. First strand synthesis was performed on 600 ng total RNA using the iScript cDNA Synthesis Kit (Bio-Rad, Hercules, CA), according to manufacturer's instructions. Gene transcripts were amplified using the primer sequences in Table 2 with iTaq Universal SYBR Green Supermix (Bio-Rad) and an Applied Biosystems 7500 Real Time PCR cycler. Amplification was confirmed with melt curve analysis to confirm the presence of a single product. Quantification of each gene was calculated using the $\Delta \Delta \mathrm{Ct}$ method with values normalized to RN18S levels and expressed relative to FT33-TAg cells.

\subsection{Clonogenicity assays}

45 or 100 cells/well were seeded per well in either 24 well or 12 well plates, respectively, and cultured for 10 days under normal culture conditions in either RPMI or patient derived ascites (see 2.8). Clonogenicity was assessed by staining colonies with crystal violet. Colonies were counted using Image $J$ and data expressed as cellular survival fractions.

Table 2

Primer sequences used for semi-quantitative real-time RT-PCR.

\begin{tabular}{ll}
\hline Primer & Sequence \\
\hline GPx3 Forward & 5'-GGGGATGTCAATGGAGAGAA-3' \\
GPx3 Reverse & 5'-TTCATGGGTTCCCAGAAGAG-3' \\
RN18S Forward & 5'-AGAAACGGCTACCACATCCA-3' \\
RN18S Reverse & 5'-CACCAGACTTGCCCTCCA-3' \\
\hline
\end{tabular}

\subsection{Cell viability assays}

Equal number of cells were seeded into 96 -well plates (5000 cells/ well) and cell viability in response to ascorbate was measured following 24 and $48 \mathrm{~h}$ after treatment. L-ascorbic acid was purchased from Sigma and final ascorbate concentrations ranged from 0.1 to $1 \mathrm{mM}$, which translates to a range of 4-40 pmol/cell [29]. Cell viability was assessed by staining with crystal violet for $10 \mathrm{~min}$, followed by washing with $\mathrm{H}_{2} \mathrm{O}$. Crystal violet dye was released from cells using $30 \%$ acetic acid and absorbance measured at $590 \mathrm{~nm}$ using a SpectraMax Paradigm Molecular Devices microplate reader. Cell viability was expressed as percentage viability relative to non-treated cells.

\subsection{Anchorage-independence survival assays}

Cell viability was also assessed via live/dead stain in untreated and treated cells during conditions of attachment and anchorage independence. Cells were cultured in anchorage-independent conditions by seeding 1000 cells/well in 96-well round-bottom ultra-low attachment plates (ULA, Corning). Cells were stained with calcein AM $(2 \mu \mathrm{M})$ and ethidium homodimer $(4 \mu \mathrm{M})$ at $37^{\circ} \mathrm{C}$ for $30 \mathrm{~min}$ following indicated times in ULA cultures. All samples were visualized using a Keyence BZX700fluorescence microscope. Viability was determined by calculating the number of live cells normalized to total number of cells using ImageJ. All experiments were performed in triplicate ( $n=4-8$ /group).

\subsection{Amplex Red hydrogen peroxide assay}

Extracellular $\mathrm{H}_{2} \mathrm{O}_{2}$ levels were assessed using the Amplex Red Hydrogen Peroxide Assay Kit, according to manufacturer's instructions (Invitrogen, \#A22188). Cell culture medium was collected 24 and $48 \mathrm{~h}$ after indicated treatments and incubated with $100 \mu \mathrm{M}$ Amplex Red reagent containing $0.2 \mathrm{U} / \mathrm{mL}$ horseradish peroxidase for $30 \mathrm{~min}$ at RT. Fluorescence was measured using a microplate reader (ex: $530 \mathrm{~nm}$, em: $590 \mathrm{~nm}$ ), and concentrations calculated based on standard curves.

\subsection{Ascites specimens}

Ovarian cancer patient ascites specimens were collected at the Penn State Cancer Institute, Hershey, PA and Women's Cancer Care, Albany NY with approval granted from the Penn State College of Medicine and the State University of New York at Albany Institutional Review Boards (IRB), respectively. All patients Ascites fluid was centrifuged at $4000 \times \mathrm{g}$ for $20 \mathrm{~min}$ at $20^{\circ} \mathrm{C}$, the acellular supernatant collected, sterile-filtered $(0.45 \mu \mathrm{m})$, and stored at $-80^{\circ} \mathrm{C}$ for further analysis.

\subsection{Static oxidation reduction potential (ORP)}

Ascites fluid was thawed on ice and $30 \mu \mathrm{l}$ applied to a filter-based sensor cell, which was inserted into the RedoxSYS ${ }^{\circledR}$ galvanostat. The sample was drawn via liquid flow along the filter channel to complete an electrochemical circuit. An initial ORP measurement was made followed by the application of a small current sweep through the sample. The primary output was a measurement of static ORP (mV), also known as the redox potential, representing the potential for electrons to move from one chemical species to another. The secondary output was capacity ORP $(\mu \mathrm{C})$, representing the amount of electrons applied over a specific time period required to reach anti-oxidant exhaustion within the sample. The cORP is derived by applying a linearly increasing oxidizing current to the sample until the charge rapidly changes between the counter and working electrodes. The amount of current required to exhaust the sample antioxidants was determined over a total $3 \mathrm{~min}$ time period. 


\subsection{Iron measurements}

Total iron content in ascites was determined using the QuantiChrom Iron Assay Kit (BioAssay Systems, DIFE-250), according to manufacturer's instructions. Absorbance was measured at $590 \mathrm{~nm}$ and iron content calculated based on standard curves.

\subsection{Statistical analysis}

All data are reported as mean \pm SEM of at least three technical replicates, from at least three independent experiments. In some indicated cases two experimental replicates were carried out, due to limited patient-derived ascites material. ImageJ was used to quantify relative fluorescence for live/dead staining and colony counting. All statistical analyses were chosen based on experimental design, as indicated, and performed using GraphPad Prism 6 (GraphPad Software, San Diego, CA). $p$ values less than 0.05 were considered significant.

\section{Results}

3.1. Ovarian cancer specimens fall into two distinct clusters of antioxidant enzyme expression, associated with GPx3 expression

To understand how ovarian cancer cells might manipulate their redox environment to survive metastatic spread through the ascites, TCGA expression and cluster analyses were carried out on known antioxidant genes (Fig. 1). We found that HGSA ovarian cancers cluster into two distinct patient populations, based on antioxidant enzyme expression (Fig. 1A). Patients in cluster 2 had a trend towards decreased overall survival compared to those in cluster 1 (Fig. 1B). Cluster 2 HGSA cases also contained a higher number of stage IV cancers, and a lower percentage of low stage cases, without detectable peritoneal metastatic lesions ( $\leq$ Stage IIC, Fig. C). From the heatmap of antioxidant gene expression it was apparent that the two patient clusters were most closely associated with expression of the extracellular glutathione peroxidase GPx3 (Fig. 1A). Among all antioxidant genes examined, high GPx3 expression displayed strongest association with a trend towards poorer overall patient survival (Fig. 1D, Log-rank $p=0.08$; Fig. S1). Patients with high GPx3 expression displayed a median survival of 38.0 months, while those with low expression displayed a median overall survival of 48.3 months.

Interestingly, the only antioxidant gene that clustered with GPx3 (Fig. 1A, Group A) was the mitochondrial superoxide dismutase Sod2. Like GPx3, cluster 2 contained predominantly samples with high Sod2 expression. Expression analysis demonstrate that GPx3 and Sod2 have a significant tendency for co-occurrence in TCGA HGSA samples (Log odds ratio: $0.47, p=0.01$ ). However, Sod2 expression did not stratify patient survival similar to GPx3 expression (Fig. 1E).

Stratifying GPx3 expression according to patient stage demonstrates that increased GPx3 expression is more prominent in higher stage cancers where peritoneal spread is readily observed ( $\geq$ stage III; Fig. 2A). To further delineate the role of GPx3 in ovarian cancer, we assessed GPx3 expression in a number of ovarian cancer cell lines and a fallopian tube (FT) epithelial cell line, representing the precursor tissue of ovarian cancer. Several cell lines of HGSA origin (HeyA8, OVCA433, OVCAR3) displayed increased GPx3 mRNA expression compared to the FT cell line, and compared to two ovarian clear cell carcinoma cell lines (ES-2, TOV-21-G; Fig. 2B). Adaptations to anchorage independence during transcoelomic metastasis is an important phenotype of ovarian cancer cells, where cells commonly aggregate to form spheroid clusters. Using ultra-low attachment (ULA) culture conditions, it was observed that OVCA420 and HeyA8 which express lower basal GPx3 expression upregulate GPx3 transcription in response to matrix detachment (Fig. 2C).

These data collectively demonstrate that ovarian cancer patient samples from HGSA patients cluster into two groups of antioxidant expression, based on either high and low GPx3 expression, with increased GPx3 expression being associated with higher stage and lower overall patient survival. Screening of ovarian cancer cell lines identifies several HGSA cell lines with either high basal GPx3 expression or induced GPx3 expression upon matrix detachment.

\subsection{GPx3 knockdown inhibits ovarian cancer cell clonogenicity and survival in response to exogenous oxidant stress}

To determine if GPx3 provides pro-tumorigenic advantages to ovarian cancer cells, two independent shRNAs targeting GPx3 transcripts were stably expressed in OVCAR3 cells that displayed highest endogenous GPx3 levels. Decreased GPx3 expression led to decreased clonogenic potential (Fig. 3A), a measure of both single cell survival and proliferation.

An important adaptation during transcoelomic metastasis is the ability to survive under anchorage independence, which is accompanied by the aggregation of cells into spheroid clusters. While GPx3 knockdown did not prevent OVCAR3 spheroid formation (Fig. 3C and D, $24 \mathrm{~h}$ in ULA plates), a loss of GPx3 expression inhibited cellular survival under prolonged anchorage independent conditions (Fig. 3C and $\mathbf{D}, 72 \mathrm{~h}$ in ULA plates). These data corroborate the importance of management of redox stress after matrix detachment, and further suggest that GPx3 might play a key role in reducing extracellular ROS.

\subsection{GPx3 is necessary for defense against exogenous sources of $\mathrm{H}_{2} \mathrm{O}_{2}$}

We next tested if GPx3 is necessary for ovarian cancer cells to deal with sources of extracellular oxidants. Cell viability assays were performed in response to ascorbate, which is oxidized in the extracellular environment to produce dehydroascorbic acid and $\mathrm{H}_{2} \mathrm{O}_{2}$ [30-32]. GPx3 knockdown resulted in increased cell death at lower ascorbate concentrations (Fig. 4A). After $24 \mathrm{~h}$ treatment, IC50 of OVCAR3 control cells was $0.42 \pm 0.01 \mathrm{mM}(16.8 \mathrm{pmol} / \mathrm{cell})$, while this was decreased to $0.26 \pm 0.01 \mathrm{mM}(10.4 \mathrm{pmol} / \mathrm{cell})$ and $0.22 \pm 0.01 \mathrm{mM}(8.8 \mathrm{pmol} /$ cell) in the two shRNA GPx3 knock-down cell lines (Fig. 4A). Similar results were observed with longer treatment times (Fig. S3A).

To verify that ascorbate treatment causes cell death through oxidant generation in the extracellular medium, we next measured extracellular $\mathrm{H}_{2} \mathrm{O}_{2}$ concentration using Amplex Red. Based on cell viability assay in Fig. 4A, we chose two concentrations of ascorbate, $0.2 \mathrm{mM}(8 \mathrm{pmol} /$ cell) and $0.3 \mathrm{mM}$ (12 pmol/cell), that were close to the IC50 of OVCAR3 cells. Compared to the untreated medium, ascorbate induced increases in $\mathrm{H}_{2} \mathrm{O}_{2}$, providing evidence that these concentrations are able to generate $\mathrm{H}_{2} \mathrm{O}_{2}$ in the media. However, knockdown of GPx3 significantly increased the amount of $\mathrm{H}_{2} \mathrm{O}_{2}$ in media of cells treated with $0.3 \mathrm{mM}$, demonstrating that GPx3 expression is important for the scavenging of excess extracellular $\mathrm{H}_{2} \mathrm{O}_{2}$ (Fig. 4B), and this correlates with cell viability studies demonstrating higher sensitivity of both GPx3 knock-down cell lines to ascorbate-mediated cell death.

Next, we determined the effects of high dose ascorbate on anchorage independent cells. Cells were treated during early culturing in ULA plates, prior to the appearance of the deleterious effects of GPx3 knockdown observed during long term anchorage independence ( $>72 \mathrm{~h}$, Fig. 3C). After $48 \mathrm{~h}$ treatment with ascorbate, anchorage-independent GPx3 knockdown resulted in a higher percentage of dead cells in anchorage-independent spheroids compared to those of control cells (Fig. 4C and D). Similar results were observed when anchorageindependent cells were treated with $20 \mu \mathrm{M} \mathrm{H}_{2} \mathrm{O}_{2}$ (Fig. S4). These data demonstrate that GPx3 protects ovarian cancer cells from exogenous oxidant insult through $\mathrm{H}_{2} \mathrm{O}_{2}$ scavenging.

\subsection{GPx3 is necessary for cell survival in ascites}

Ascites accumulation is one of the clinical symptoms of advanced ovarian cancer. During transcoelomic metastasis, ovarian cancer cells 

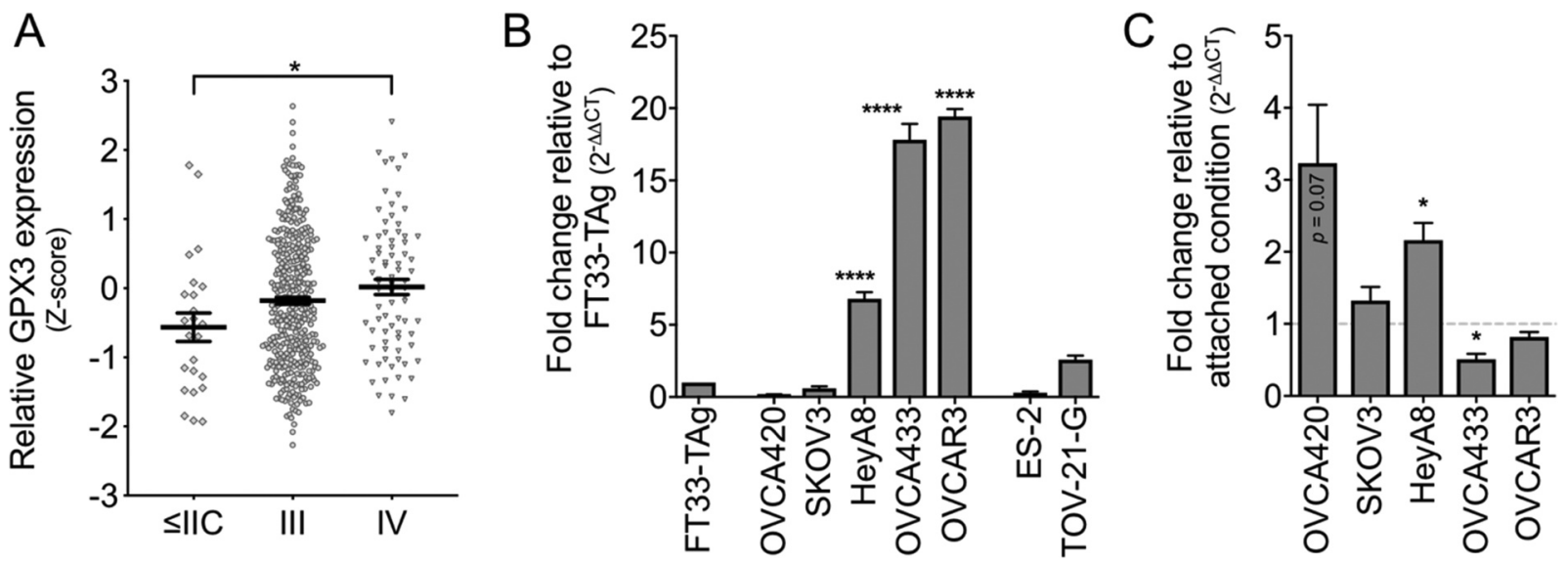

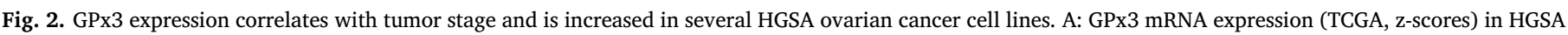

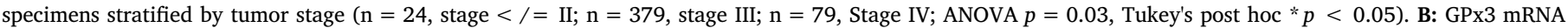

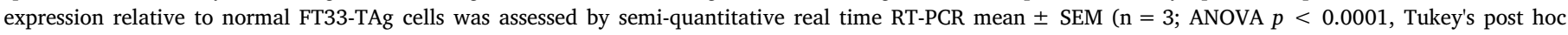

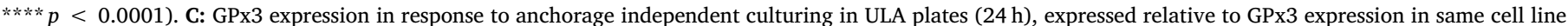
under attached conditions (mean $\pm \mathrm{SEM}, \mathrm{n}=3$; $t$-test relative to attached conditions ${ }^{*} p<0.05$ ).

are exposed to ascites when they disseminate via this fluid throughout the peritoneal cavity. To determine if GPx3 is specifically required for survival in ascites with high oxidant stress, we measured the oxidation reduction potential and iron content in malignant ascites of 10 HGSA patients and one case of each malignant ascites from a granulosa ovarian tumor, endometrial ovarian tumor and a GI tumor of unknown histological origin. Ascites oxidation reduction potential (ORP), was determined by measuring static (s) and capacity (c) ORP using the RedoxSYS (Fig. 5A and B, Fig. S5). Ascites from patients presenting at the clinic with $\geq$ Stage IIIC HGSA tumors had a mean sORP of $129.1 \mathrm{mV} \pm 23.7$, with a large variability between ascites specimens (Range: 90.5-165.4 mV, Fig. 5A). Similarly, HGSA ascites iron content ranged from undetectable to $12.0 \mu \mathrm{M}$ (Fig. 5A). In comparison, iron content in ascites from a GI tumor displayed the greatest iron content $(28.8 \mu \mathrm{M})$, while ascites from an endometrial ovarian cancer had the highest sORP (205.2 mV, Fig. 5B). Further, we found a significant positive correlation between SORP and total iron levels of malignant ascites (Fig. 5B), while cORP negatively correlated with iron content and sORP (Fig. S5).

To test if GPx3 provides ovarian cancer cells with a survival advantage when exposed to this metastatic medium, we performed clonogenicity assays by seeding OVCAR3 control and shRNA GPx3 knockdown cells in ascites fluid from four ovarian cancer patients, representing fluid with high sORP and high iron (AF15), median sORP and high iron (AF3), median sORP and low iron (AF2, AF6). While clonogenicity of control cells was decreased in response to ascites compared to RPMI media, GPx3 knockdown further prevented colony formation in all ascites samples regardless of their iron or sORP status (Fig. 5C and D).

\section{Discussion}

Cancer metastasis is a complex, multi-stage process during which cancer cells undergo rapid adaptation to changing tumor environments. One such adaptation is acquisition of antioxidant defenses against oxidative stress [5]. In addition to overcoming anchorage independent cell death (anoikis), epithelial ovarian cancer cells face the unique ascites tumor environment during transcoelomic metastasis in the peritoneal cavity. Using TCGA expression data of HGSAs we set out to identify patterns of antioxidant enzyme expression that are associated with advanced stage disease, and discovered that patients clustered into two distinct groups based on GPx3 expression. GPx3 was also the primary antioxidant associated negatively with patient outcome, with tumors displaying increased GPx3 expression correlating with a decrease in median patient survival by 9.3 months. Interestingly, high expression of other antioxidant enzymes appears to be associated with better prognosis. Some antioxidant genes that cluster together in group $\mathrm{C}$ are associated with improved overall survival (Fig. 1 and Fig. S2). For example, high expression of Sod1 in HGSA tumors improves patient median survival by 10 months compared to tumors with low Sod1 levels $(p=0.03$, Fig. S2A).

Decreased GPx3 expression has been observed in a number of tumor types, including prostate, gastric, cervical, colorectal and thyroid cancers [17-20], and this loss associated with chemosensitivity [21,22]. Decreased GPx3 expression has largely been attributed to GPX3 promoter methylation $[17,18,33,34]$. However, increased GPx3 expression has also been associated with some tumor types and during different stages of tumor progression, including high GPx3 levels in leukemic stem cells [35]. Increased GPx3 expression in the less common histological subtype of ovarian cancer, clear cell carcinoma was previously demonstrated [36] and associated with chemoresistance [23,24]. Our study demonstrates that high GPx3 expression is also associated with a subgroup of the more common HGSA ovarian cancer subtype, and that high expression is more common in advanced stage tumors and associated with poor patient survival. While GPx3 levels in serum of serous ovarian cancers were previously shown to be lower than controls subjects [37], proteomics analysis of ascites, revealed enrichment of GPx3 in patient ascites [25]. We argue that cancers where extracellular scavenging of oxidants is an important requirement for metastasis require the expression of GPx3. Here, we present the first evidence that GPx3 may have a specific role in aiding cellular survival in patient ascites.

Given that GPx3 is an extracellular antioxidant further supports the notion that extracellular antioxidant defenses are of importance to ovarian cancer progression, and alludes to their role in dealing with extracellular sources of oxidants in the tumor microenvironment. We present evidence that GPx3 is necessary for clonogenic survival, a measure of both single cell survival and proliferation, as well as longterm anchorage independent survival of ovarian cancer cells (Fig. 3). It is noteworthy that there was no significant difference in cell viability between control and GPx3 knock-down cells in attached conditions, suggesting that GPx3-mediated scavenging of extracellular $\mathrm{H}_{2} \mathrm{O}_{2}$ becomes most critical when cells are undergoing oxidative stress associated with metastatic processes such as matrix detachment.

In this context, we find that GPx3 is also an important factor to aid cellular survival in changing tumor environments, as we demonstrate the necessary of GPx3 for clonogenic survival in patient-derived ascites fluid (Fig. 5). These data suggest that extracellular $\mathrm{H}_{2} \mathrm{O}_{2}$ scavenging is 

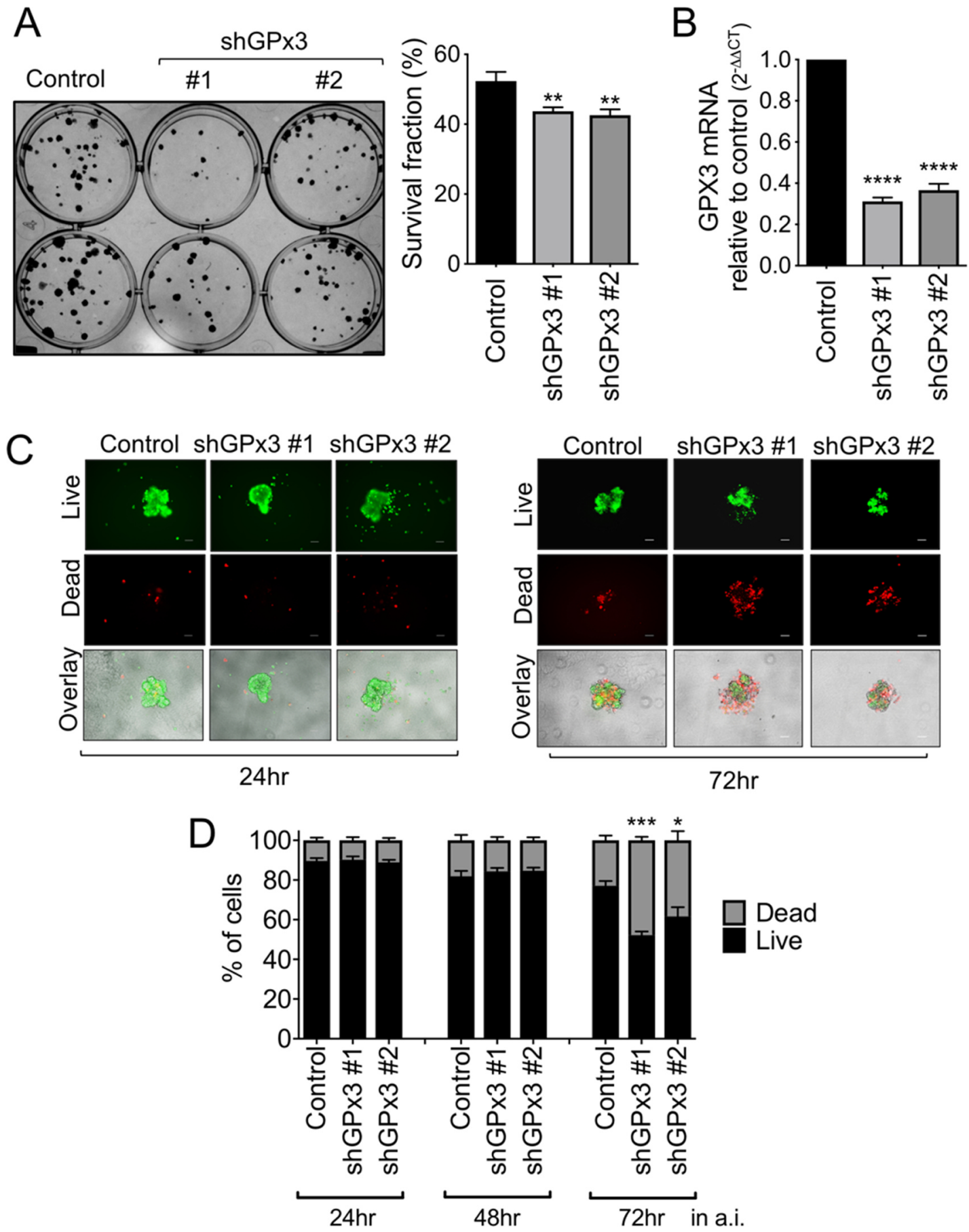

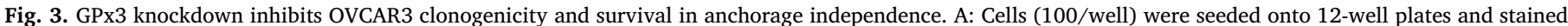

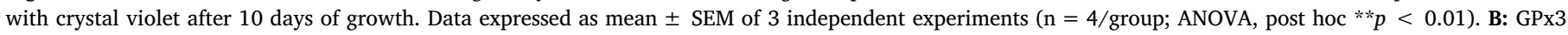

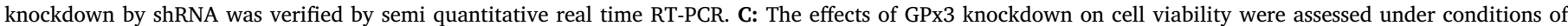

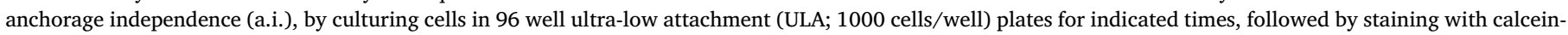

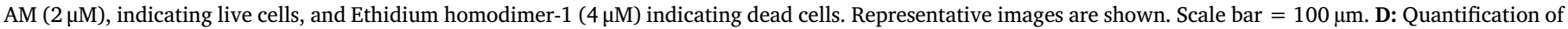
live/dead staining using ImageJ. Data expressed as mean \pm SEM ( $\mathrm{n}=4-8$ /group; One-way ANOVA, Tukey's post hoc, $* * p<0.01, * * * *<0.0001)$.

an important aspect of survival through the ascites and implies that this medium may be characterized by increased oxidative stress. While the lack of sensitivity of the AmplexRed assay prevented us to accurately measure $\mathrm{H}_{2} \mathrm{O}_{2}$ levels in ascites fluid, we observed that static oxidation reduction potential (ORP) was greatly variable among HGSA ascites specimens, ranging from 90.5 to $165.4 \mathrm{mV}$, and not specifically elevated compared to normal plasma sORP values that have been previously reported to range from 120 to $180 \mathrm{mV}$ [38-40]. Canton-Romero et al. recently demonstrated that ovarian cancer ascites display increased levels of 8-isoprostane and lipid peroxidation products compared to normal plasma [16]. Interestingly, it was also reported that ascites concomitantly increase their total antioxidant capacity [16]. No correlation between cell survival and the levels of iron or oxidation reduction potential of ascites could be identified in our limited patient sample. A larger cohort of patient samples will aid in delineating if a high oxidative environment is more inhibitory to metastatic progression through the ascites [5]. Unfortunately, we were unable to reliably detect glutathione in the ascites, and recognize that further analyses of 
A

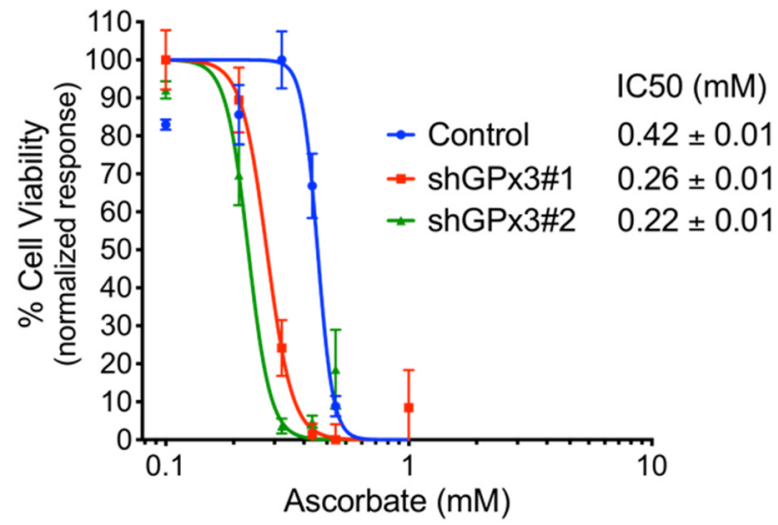

B

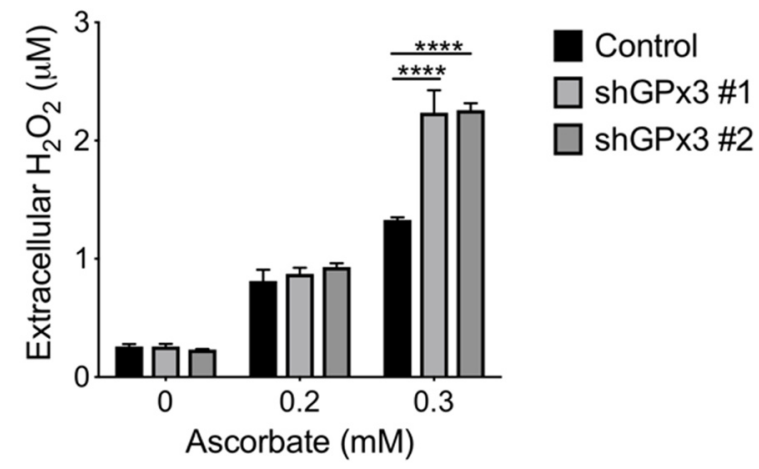

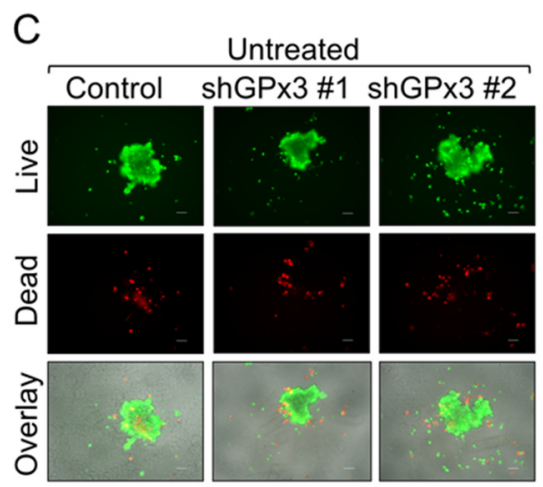
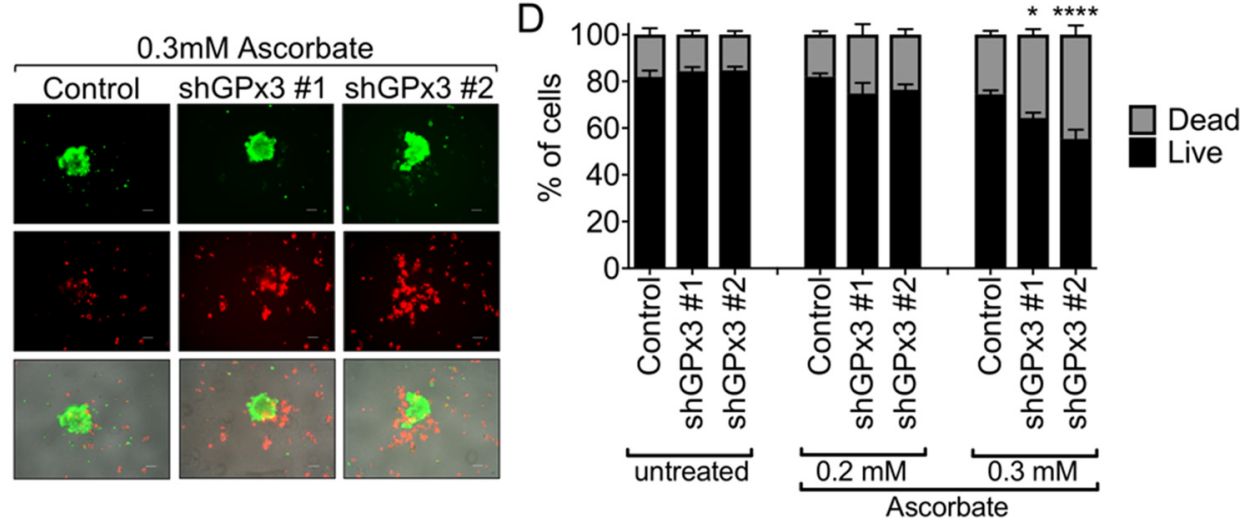

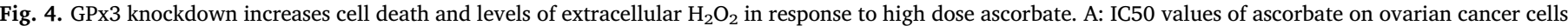

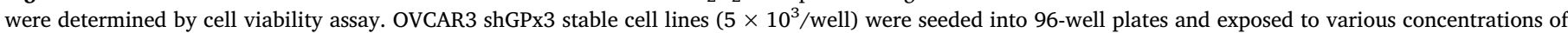

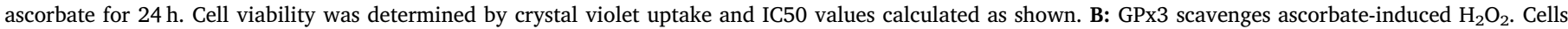

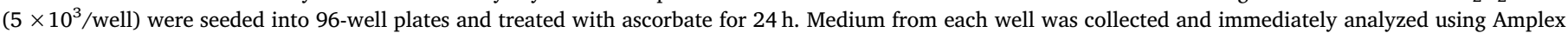

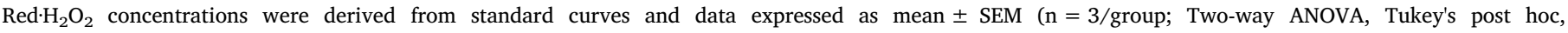

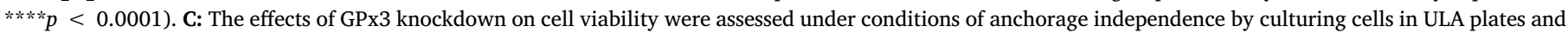

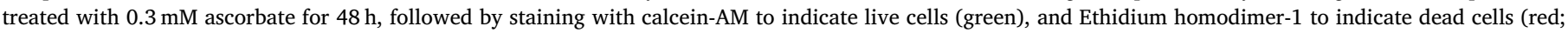

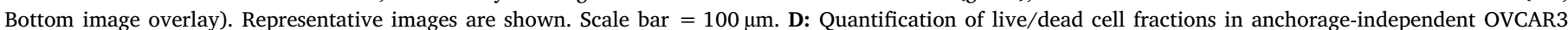

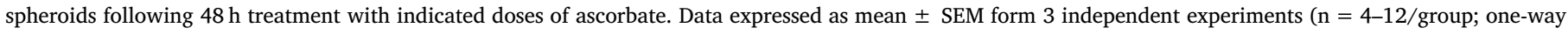
ANOVA, Tukey's post hoc, $\left.{ }^{*} p<0.05,{ }^{*} * * * p<0.0001\right)$.

ascites composition are necessary to fully discover the role of oxidant stress management for successful transcoelomic metastasis through this medium.

Our data also highlight that the $\mathrm{H}_{2} \mathrm{O}_{2}$ scavenging function of GPx3 is necessary for cells to deal with sources of exogenous $\mathrm{H}_{2} \mathrm{O}_{2}$ (Fig. 4). In our study we used the pro-oxidant ascorbate to demonstrate this. High dose ascorbate has been demonstrated to induce selective cytotoxicity towards a variety of cancer types $[30,31,41,42]$. The IC50 dose for OVCAR3 cells (16.8 pmol/cell) is within the cytotoxic dose reported previously for non-small cell lung cancer and glioblastoma cells [43], and the use of high dose ascorbate as an anti-cancer adjuvant agent has been tested with some promise in early clinical trials of advanced stage cancers [30,43-47]. IV ascorbate therapy was also trialed in combination with carboplatin and paclitaxel in a small cohort of ovarian cancer patients [42]. While there was a trend towards improvement in survival, this was not significant. Encouragingly, there was a significant improvement in decreasing adverse side effects with combination ascorbate treatment in patients [42]. It has previously been demonstrated that a major mechanism for ascorbate toxicity is the extracellular generation of $\mathrm{H}_{2} \mathrm{O}_{2}[30,41,43]$. While it is still debated whether extracellular iron is of important for the oxidation of ascorbate [32,48], a disruption of iron homeostasis in cancer cells aids the cytotoxicity of ascorbate, either by inducing ascorbate oxidation, and/or through Fenton chemistry of the generated $\mathrm{H}_{2} \mathrm{O}_{2}$ resulting in oxidative damage of cellular macromolecules $[30,41,43]$. Moreover, it is thought that an inability of tumor cells to adequately scavenge these species, either due to changes in antioxidant enzyme activity and/or the depletion of reducing equivalents such as glutathione (GSH) and nicotinamide adenine dinucleotide phosphate (NADPH) further enhances oxidant stress in response to ascorbate $[30,32,44,45]$.

As reported previously $[30,41,43]$, we similarly demonstrate that $\mathrm{H}_{2} \mathrm{O}_{2}$ is extracellularly generated with ascorbate treatment (Fig. 4B). However, the presence of GPx3 significantly improves extracellular $\mathrm{H}_{2} \mathrm{O}_{2}$ scavenging ability of ovarian cancer cells and prevents cell death in response to ascorbate treatment. These data indicate that extracellular antioxidant enzyme expression can affect ascorbate cytotoxicity, and these expression patterns should be considered in the patient population prior to use of pharmacological ascorbate in the treatment of ovarian cancer. As demonstrate by cluster analysis of HGSA patients, $45 \%$ of patients cluster together based on high GPx3 expression (Fig. 1). For these patients, ascorbate treatment may prove to be less effective than patients with low GPx3 expression in cluster 1 .

In conclusion, our data demonstrate that HGSA ovarian cancers cluster into distinct groups of high and low GPx3 expression. GPx3 is necessary for HGSA ovarian cancer cellular survival in the unique ascites tumor environment and protects against extracellular sources of oxidative stress, implicating GPx3 as an important adaptation for transcoelomic metastasis.

\section{Acknowledgements}

We thank Ms. Sara Shimko and Ms. Gina Deiter for technical 


A
\begin{tabular}{|l|l|l|}
\hline High Grade Serous Adenocarcinoma \\
\hline & Mean \pm S.D. & Median (Min. - Max.) \\
\hline sORP $(m \mathrm{~m}) \mathrm{n}=10$ & $129.1 \pm 23.6$ & $133.6(90.5-165.4)$ \\
\hline $\operatorname{cORP}(\mu \mathrm{C}) \mathrm{n}=10$ & $0.66 \pm 0.80$ & $0.37(0.11-2.68)$ \\
\hline Total Iron $(\mu \mathrm{M}) \mathrm{n}=9$ & $7.0 \pm 3.8$ & $9.0(\mathrm{n} / \mathrm{d}-12.0)$ \\
\hline
\end{tabular}

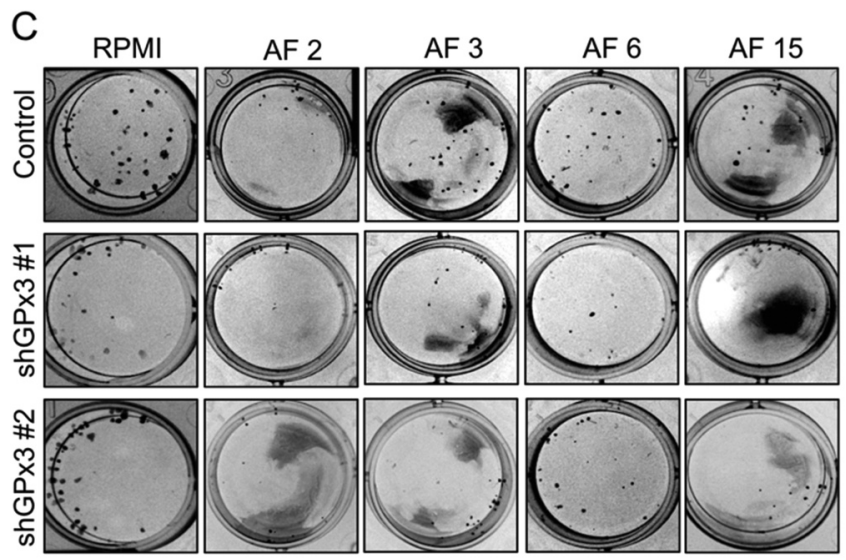

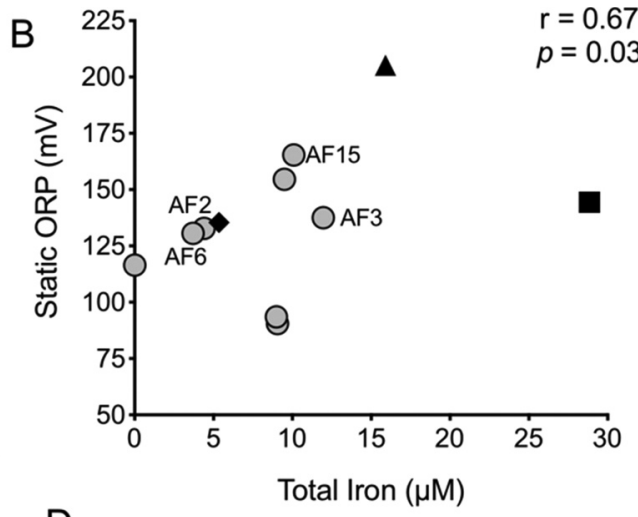

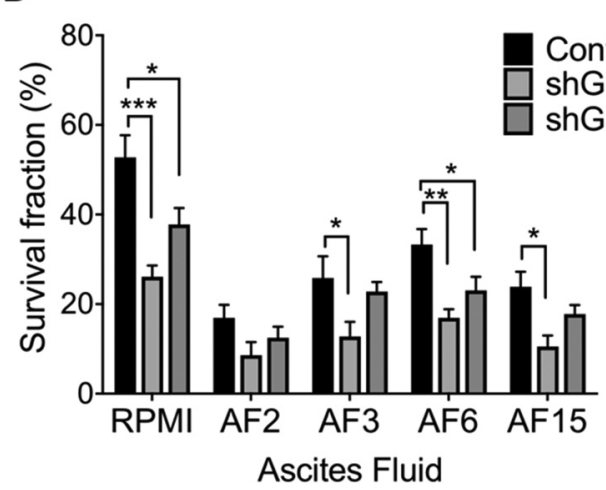

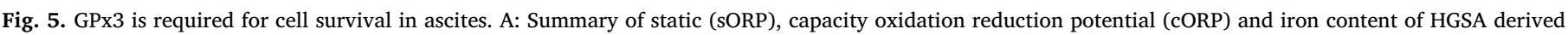

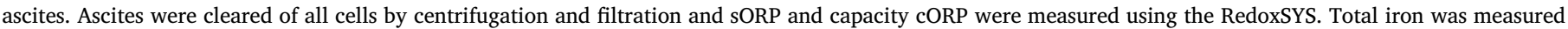

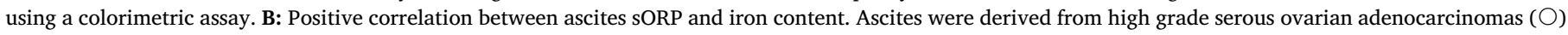

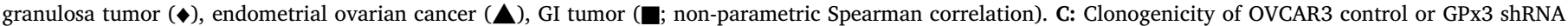

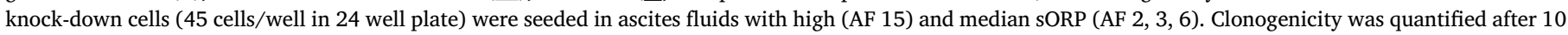

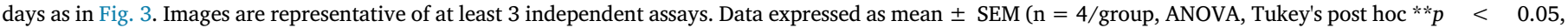
$* * p<0.01, * * * p<0.001)$. D: Quantification of clonogenicity using ImageJ.

assistance.

\section{Funding}

This work was supported by the Rivkin Center for Ovarian Cancer, Seattle, WA (Pilot Award). Collection of ascites was partially supported by the Office of the Assistant Secretary of Defense for Health Affairs, through the Ovarian Cancer Research Program under Award No. W81XWH-16-1-0117. Opinions, interpretations, conclusions and recommendations are those of the author and are not necessarily endorsed by the Department of Defense.

\section{Appendix A. Supporting information}

Supplementary data associated with this article can be found in the online version at doi:10.1016/j.redox.2018.11.009.

\section{References}

[1] L.A. Torre, B. Trabert, C.E. DeSantis, K.D. Miller, G. Samimi, C.D. Runowicz, M.M. Gaudet, A. Jemal, R.L. Siegel, Ovarian cancer statistics, 2018, CA Cancer J. Clin. 68 (4) (2018) 284-296, https://doi.org/10.3322/caac.21456.

[2] B. Davidson, Ovarian carcinoma and serous effusions. Changing views regarding tumor progression and review of current literature, Anal. Cell.Pathol. J. Eur. Soc. Anal. Cell. Pathol. 23 (3-4) (2001) 107-128.

[3] A. Latifi, R.B. Luwor, M. Bilandzic, S. Nazaretian, K. Stenvers, J. Pyman, H. Zhu, E.W. Thompson, M.A. Quinn, J.K. Findlay, N. Ahmed, Isolation and characterization of tumor cells from the ascites of ovarian cancer patients: molecular phenotype of chemoresistant ovarian tumors, PLoS One 7 (10) (2012) e46858, https://doi.org/ 10.1371/journal.pone.0046858.

[4] D.S. Tan, R. Agarwal, S.B. Kaye, Mechanisms of transcoelomic metastasis in ovarian cancer, Lancet Oncol. 7 (11) (2006) 925-934, https://doi.org/10.1016/S1470-
2045(06)70939-1.

[5] E. Piskounova, M. Agathocleous, M.M. Murphy, Z. Hu, S.E. Huddlestun, Z. Zhao, A.M. Leitch, T.M. Johnson, R.J. DeBerardinis, S.J. Morrison, Oxidative stress inhibits distant metastasis by human melanoma cells, Nature 527 (7577) (2015) 186-191, https://doi.org/10.1038/nature15726.

[6] Z.T. Schafer, A.R. Grassian, L. Song, Z. Jiang, Z. Gerhart-Hines, H.Y. Irie, S. Gao, P. Puigserver, J.S. Brugge, Antioxidant and oncogene rescue of metabolic defects caused by loss of matrix attachment, Nature 461 (7260) (2009) 109-113, https:// doi.org/10.1038/nature08268.

[7] C.A. Davison, S.M. Durbin, M.R. Thau, V.R. Zellmer, S.E. Chapman, J. Diener, C. Wathen, W.M. Leevy, Z.T. Schafer, Antioxidant enzymes mediate survival of breast cancer cells deprived of extracellular matrix, Cancer Res. 73 (12) (2013) 3704-3715, https://doi.org/10.1158/0008-5472.CAN-12-2482.

[8] G.M. DeNicola, F.A. Karreth, T.J. Humpton, A. Gopinathan, C. Wei, K. Frese, D. Mangal, K.H. Yu, C.J. Yeo, E.S. Calhoun, F. Scrimieri, J.M. Winter, R.H. Hruban, C. Iacobuzio-Donahue, S.E. Kern, I.A. Blair, D.A. Tuveson, Oncogene-induced Nrf2 transcription promotes ROS detoxification and tumorigenesis, Nature 475 (7354) (2011) 106-109, https://doi.org/10.1038/nature10189.

[9] S. Dey, C.M. Sayers, I.I. Verginadis, S.L. Lehman, Y. Cheng, G.J. Cerniglia, S.W. Tuttle, M.D. Feldman, P.J. Zhang, S.Y. Fuchs, J.A. Diehl, C. Koumenis, ATF4dependent induction of heme oxygenase 1 prevents anoikis and promotes metastasis, J. Clin. Investig. 125 (7) (2015) 2592-2608, https://doi.org/10.1172/ JCI78031.

[10] N. Hempel, P.M. Carrico, J.A. Melendez, Manganese superoxide dismutase (Sod2) and redox-control of signaling events that drive metastasis, Anti-Cancer Agents Med. Chem. 11 (2) (2011) 191-201.

[11] N. Ahmed, K.L. Stenvers, Getting to know ovarian cancer ascites: opportunities for targeted therapy-based translational research, Front. Oncol. 3 (2013) 256, https:// doi.org/10.3389/fonc. 2013.00256.

[12] M. Plante, S.C. Rubin, G.Y. Wong, M.G. Federici, C.L. Finstad, G.A. Gastl, Interleukin-6 level in serum and ascites as a prognostic factor in patients with epithelial ovarian cancer, Cancer 73 (7) (1994) 1882-1888.

[13] D. Lane, I. Matte, C. Rancourt, A. Piché, Prognostic significance of IL-6 and IL-8 ascites levels in ovarian cancer patients, BMC Cancer 11 (2011) 210, https://doi. org/10.1186/1471-2407-11-210.

[14] X. Fang, S. Yu, R.C. Bast, S. Liu, H.J. Xu, S.X. Hu, R. LaPushin, F.X. Claret, B.B. Aggarwal, Y. Lu, G.B. Mills, Mechanisms for lysophosphatidic acid-induced cytokine production in ovarian cancer cells, J. Biol. Chem. 279 (10) (2004) 
9653-9661, https://doi.org/10.1074/jbc.M306662200.

[15] A. Mukherjee, J. Wu, S. Barbour, X. Fang, Lysophosphatidic acid activates lipogenic pathways and de novo lipid synthesis in ovarian cancer cells, J. Biol. Chem. 287 (30) (2012) 24990-25000, https://doi.org/10.1074/jbc.M112.340083.

[16] J.C. Cantón-Romero, A.G. Miranda-Díaz, J.L. Bañuelos-Ramírez, S. Carrillo-Ibarra, S. Sifuentes-Franco, J.A. Castellanos-González, A.D. Rodríguez-Carrizalez, Markers of oxidative stress and inflammation in ascites and plasma in patients with platinum-sensitive, platinum-resistant, and platinum-refractory epithelial ovarian cancer, Oxid. Med. Cell. Longev. 2017 (2017) 2873030, https://doi.org/10.1155/ 2017/2873030

[17] Y.P. Yu, G. Yu, G. Tseng, K. Cieply, J. Nelson, M. Defrances, R. Zarnegar, G. Michalopoulos, J.H. Luo, Glutathione peroxidase 3, deleted or methylated in prostate cancer, suppresses prostate cancer growth and metastasis, Cancer Res. 67 (17) (2007) 8043-8050, https://doi.org/10.1158/0008-5472.CAN-07-0648.

[18] X. Zhang, J.J. Yang, Y.S. Kim, K.Y. Kim, W.S. Ahn, S. Yang, An 8-gene signature, including methylated and down-regulated glutathione peroxidase 3, of gastric cancer, Int. J. Oncol. 36 (2) (2010) 405-414.

[19] X. Zhang, Z. Zheng, S. Yingji, H. Kim, R. Jin, L. Renshu, D.Y. Lee, M.R. Roh, S. Yang, Downregulation of glutathione peroxidase 3 is associated with lymph node metastasis and prognosis in cervical cancer, Oncol. Rep. 31 (6) (2014) 2587-2592, https://doi.org/10.3892/or.2014.3152.

[20] H. Zhao, J. Li, X. Li, C. Han, Y. Zhang, L. Zheng, M. Guo, Silencing GPX3 expression promotes tumor metastasis in human thyroid cancer, Curr. Protein Pept. Sci. 16 (4) (2015) 316-321.

[21] B. Chen, X. Rao, M.G. House, K.P. Nephew, K.J. Cullen, Z. Guo, GPx3 promoter hypermethylation is a frequent event in human cancer and is associated with tumorigenesis and chemotherapy response, Cancer Lett. 309 (1) (2011) 37-45, https://doi.org/10.1016/j.canlet.2011.05.013.

[22] L. Pelosof, S. Yerram, T. Armstrong, N. Chu, L. Danilova, B. Yanagisawa M. Hidalgo, N. Azad, J.G. Herman, GPX3 promoter methylation predicts platinum sensitivity in colorectal cancer, Epigenetics 12 (7) (2017) 540-550, https://doi.org/ 10.1080/15592294.2016.1265711.

[23] H.J. Lee, J.H. Do, S. Bae, S. Yang, X. Zhang, A. Lee, Y.J. Choi, D.C. Park, W.S. Ahn, Immunohistochemical evidence for the over-expression of glutathione peroxidase 3 in clear cell type ovarian adenocarcinoma, Med Oncol. 28 (Suppl 1) (2011) S522-S527, https://doi.org/10.1007/s12032-010-9659-0.

[24] Y. Saga, M. Ohwada, M. Suzuki, R. Konno, J. Kigawa, S. Ueno, H. Mano, Glutathione peroxidase 3 is a candidate mechanism of anticancer drug resistance of ovarian clear cell adenocarcinoma, Oncol. Rep. 20 (6) (2008) 1299-1303.

[25] C. Kuk, V. Kulasingam, C.G. Gunawardana, C.R. Smith, I. Batruch, E.P. Diamandis, Mining the ovarian cancer ascites proteome for potential ovarian cancer biomarkers, Mol. Cell. Proteom. 8 (4) (2009) 661-669, https://doi.org/10.1074/mcp. M800313-MCP200.

[26] N. Avissar, D.B. Ornt, Y. Yagil, S. Horowitz, R.H. Watkins, E.A. Kerl, K. Takahashi, I.S. Palmer, H.J. Cohen, Human kidney proximal tubules are the main source of plasma glutathione peroxidase, Am. J. Physiol. 266 (2 Pt 1) (1994) C367-C375, https://doi.org/10.1152/ajpcell.1994.266.2.C367.

[27] E. Cerami, J. Gao, U. Dogrusoz, B.E. Gross, S.O. Sumer, B.A. Aksoy, A. Jacobsen, C.J. Byrne, M.L. Heuer, E. Larsson, Y. Antipin, B. Reva, A.P. Goldberg, C. Sander, N. Schultz, The cBio cancer genomics portal: an open platform for exploring multidimensional cancer genomics data, Cancer Discov. 2 (5) (2012) 401-404, https:// doi.org/10.1158/2159-8290.CD-12-0095.

[28] U. Dier, D.H. Shin, L.P. Hemachandra, L.M. Uusitalo, N. Hempel, Bioenergetic analysis of ovarian cancer cell lines: profiling of histological subtypes and identification of a mitochondria-defective cell line, PLoS One 9 (5) (2014) e98479, https://doi.org/10.1371/journal.pone.0098479.

[29] C.M. Doskey, T.J. van 't Erve, B.A. Wagner, G.R. Buettner, Moles of a substance per cell is a highly informative dosing metric in cell culture, PLoS One 10 (7) (2015) e0132572, https://doi.org/10.1371/journal.pone.0132572.

[30] Q. Chen, M.G. Espey, M.C. Krishna, J.B. Mitchell, C.P. Corpe, G.R. Buettner, E. Shacter, M. Levine, Pharmacologic ascorbic acid concentrations selectively kill cancer cells: action as a pro-drug to deliver hydrogen peroxide to tissues, Proc. Natl. Acad. Sci. USA 102 (38) (2005) 13604-13609, https://doi.org/10.1073/pnas. 0506390102.

[31] O. Chen, M.G. Espey, A.Y. Sun, J.H. Lee, M.C. Krishna, E. Shacter, P.L. Choyke, C. Pooput, K.L. Kirk, G.R. Buettner, M. Levine, Ascorbate in pharmacologic concentrations selectively generates ascorbate radical and hydrogen peroxide in extracellular fluid in vivo, Proc. Natl. Acad. Sci. USA 104 (21) (2007) 8749-8754, https://doi.org/10.1073/pnas.0702854104.
[32] J. Du, B.A. Wagner, G.R. Buettner, J.J. Cullen, Role of labile iron in the toxicity of pharmacological ascorbate, Free Radic. Biol. Med. 84 (2015) 289-295, https://doi. org/10.1016/j.freeradbiomed.2015.03.033.

[33] O.J. Lee, R. Schneider-Stock, P.A. McChesney, D. Kuester, A. Roessner, M. Vieth, C.A. Moskaluk, W. El-Rifai, Hypermethylation and loss of expression of glutathione peroxidase-3 in Barrett's tumorigenesis, Neoplasia 7 (9) (2005) 854-861.

[34] M.F. Kaiser, D.C. Johnson, P. Wu, B.A. Walker, A. Brioli, F. Mirabella, C.P. Wardell, L. Melchor, F.E. Davies, G.J. Morgan, Global methylation analysis identifies prognostically important epigenetically inactivated tumor suppressor genes in multiple myeloma, Blood 122 (2) (2013) 219-226, https://doi.org/10.1182/blood-2013-03487884.

[35] O. Herault, K.J. Hope, E. Deneault, N. Mayotte, J. Chagraoui, B.T. Wilhelm, S. Cellot, M. Sauvageau, M.A. Andrade-Navarro, J. Hebert, G. Sauvageau, A role for GPx3 in activity of normal and leukemia stem cells, J. Exp. Med. 209 (5) (2012) 895-901, https://doi.org/10.1084/jem.20102386.

[36] C.D. Hough, K.R. Cho, A.B. Zonderman, D.R. Schwartz, P.J. Morin, Coordinately upregulated genes in ovarian cancer, Cancer Res. 61 (10) (2001) 3869-3876.

[37] D. Agnani, O. Camacho-Vanegas, C. Camacho, S. Lele, K. Odunsi, S. Cohen, P. Dottino, J.A. Martignetti, Decreased levels of serum glutathione peroxidase 3 are associated with papillary serous ovarian cancer and disease progression, J. Ovarian Res. 4 (2011) 18, https://doi.org/10.1186/1757-2215-4-18.

[38] G. Bobe, T.J. Cobb, S.W. Leonard, S. Aponso, C.B. Bahro, D. Koley, E. Mah, R.S. Bruno, M.G. Traber, Increased static and decreased capacity oxidation-reduction potentials in plasma are predictive of metabolic syndrome, Redox Biol. 12 (2017) 121-128, https://doi.org/10.1016/j.redox.2017.02.010.

[39] L.T. Rael, R. Bar-Or, C.W. Mains, D.S. Slone, A.S. Levy, D. Bar-Or, Plasma oxidationreduction potential and protein oxidation in traumatic brain injury, J. Neurotrauma 26 (8) (2009) 1203-1211, https://doi.org/10.1089/neu.2008-0816.

[40] D. Stagos, N. Goutzourelas, A.M. Ntontou, I. Kafantaris, C.K. Deli, A. Poulios, A.Z. Jamurtas, D. Bar-Or, D. Kouretas, Assessment of eccentric exercise-induced oxidative stress using oxidation-reduction potential markers, Oxid. Med. Cell. Longev. 2015 (2015) 204615, https://doi.org/10.1155/2015/204615.

[41] J. Du, S.M. Martin, M. Levine, B.A. Wagner, G.R. Buettner, S.H. Wang, A.F. Taghiyev, C. Du, C.M. Knudson, J.J. Cullen, Mechanisms of ascorbate-induced cytotoxicity in pancreatic cancer, Clin. Cancer Res. 16 (2) (2010) 509-520, https:// doi.org/10.1158/1078-0432.CCR-09-1713.

[42] Y. Ma, J. Chapman, M. Levine, K. Polireddy, J. Drisko, Q. Chen, High-dose parenteral ascorbate enhanced chemosensitivity of ovarian cancer and reduced toxicity of chemotherapy, Sci. Transl. Med. 6 (222) (2014) 222ra18, https://doi.org/10. 1126/scitranslmed.3007154.

[43] J.D. Schoenfeld, Z.A. Sibenaller, K.A. Mapuskar, B.A. Wagner, K.L. Cramer-Morales, M. Furqan, S. Sandhu, T.L. Carlisle, M.C. Smith, T. Abu Hejleh, D.J. Berg, J. Zhang, J. Keech, K.R. Parekh, S. Bhatia, V. Monga, K.L. Bodeker, L. Ahmann, S. Vollstedt, H. Brown, E.P. Shanahan Kauffman, M.E. Schall, R.J. Hohl, G.H. Clamon, J.D. Greenlee, M.A. Howard, M.K. Schultz, B.J. Smith, D.P. Riley, F.E. Domann, J.J. Cullen, G.R. Buettner, J.M. Buatti, D.R. Spitz, B.G. Allen, $\mathrm{O}_{2}(-)$ and $\mathrm{H}_{2} \mathrm{O}_{2-}$ mediated disruption of fe metabolism causes the differential susceptibility of NSCLC and GBM cancer cells to pharmacological ascorbate, Cancer Cell. 31 (4) (2017) 487-500, https://doi.org/10.1016/j.ccell.2017.02.018 (e8).

[44] E. Cameron, A. Campbell, The orthomolecular treatment of cancer. II. Clinical trial of high-dose ascorbic acid supplements in advanced human cancer, Chem.-Biol. Interact. 9 (4) (1974) 285-315.

[45] M. Levine, S.J. Padayatty, M.G. Espey, Vitamin C: a concentration-function approach yields pharmacology and therapeutic discoveries, Adv. Nutr. 2 (2) (2011) 78-88, https://doi.org/10.3945/an.110.000109.

[46] L.J. Hoffer, M. Levine, S. Assouline, D. Melnychuk, S.J. Padayatty, K. Rosadiuk, C. Rousseau, L. Robitaille, W.H. Miller Jr., Phase I clinical trial of i.v. ascorbic acid in advanced malignancy, Ann. Oncol. : Off. J. Eur. Soc. Med. Oncol. / ESMO 19 (11) (2008) 1969-1974, https://doi.org/10.1093/annonc/mdn377.

[47] D.A. Monti, E. Mitchell, A.J. Bazzan, S. Littman, G. Zabrecky, C.J. Yeo, M.V. Pillai, A.B. Newberg, S. Deshmukh, M. Levine, Phase I evaluation of intravenous ascorbic acid in combination with gemcitabine and erlotinib in patients with metastatic pancreatic cancer, PLoS One 7 (1) (2012) e29794, https://doi.org/10.1371/journal pone.0029794.

[48] M. Mojic, J. Bogdanovic Pristov, D. Maksimovic-Ivanic, D.R. Jones, M. Stanic, S. Mijatovic, I. Spasojevic, Extracellular iron diminishes anticancer effects of vitamin C: an in vitro study, Sci. Rep. 4 (2014) 5955, https://doi.org/10.1038/ srep05955. 